\title{
Anaerobic Treatment of Oily Wastewater Using A Biofilm-Electrode Reactor: A Kinetic Study And Energy Consumption
}

\section{Amir Mirshafiee}

Tarbiat Modares University

Abbas Rezaee ( $\square$ abbasrezaee@yahoo.com )

Tarbiat Modares University

\section{Research Article}

Keywords: Bioelectrochemical, Anaerobic, Oily Wastewater, Kinetic, Stover-Kincannon model

Posted Date: May 5th, 2021

DOl: https://doi.org/10.21203/rs.3.rs-421790/v1

License: (c) (1) This work is licensed under a Creative Commons Attribution 4.0 International License.

Read Full License 


\section{Study and Energy Consumption}

$4 \quad{ }^{1}$ Department of Environmental Health, Faculty of Medical Sciences, Tarbiat Modares

5 University, Tehran, Iran

$6{ }^{2}$ Health Research Center, Life Style Institute, Baqiyatallah University of Medical Sciences, 7 Tehran, Iran

$8 \quad *$ Corresponding author: Email address:rezaee@modares.ac.ir (A. Rezaee)

10 Abstract

11 The present study introduced a laboratory-scale, anaerobic treatment system for the removal of oil

12 from synthetic wastewr using a biofilm-electrode reactor (BER). The operating parameters of

13 current intensity, initial concentration, reaction time, and supporting electrolyte were investigated.

14 The results of the present study showed that the optimal conditions were: a current intensity of 15

$15 \mathrm{~mA}, \mathrm{COD}$ concentration of $1500 \mathrm{mg} / \mathrm{L}$, a reaction time of three days, and a supporting electrolyte

$16(\mathrm{NaCl})$ of $150 \mathrm{mg} / \mathrm{L}$. The highest efficiency for the removal of COD was $86.7 \%$ using the

17 introduced method, while it was $65.9 \%$ using biological processes. Increased efficiency was

18 attributed to the employment of the proposed bioelectrochemical system that stimulated bacterial

19 growth. In the present study, the energy consumed by the bioelectrochemical system was 1.914

$20 \mathrm{kWh} / \mathrm{m}^{3}$. The kinetic study indicated that the removal reaction was more consistent with the 
21 modified Stover-Kincannon model. The present study findings indicated that BER is a promising

22 method for the treatment of oil-contaminated wastewaters.

24 Keywords: Bioelectrochemical, Anaerobic, Oily Wastewater, Kinetic, Stover-Kincannon model

\section{Introduction}

27 Recently, oil-contaminated wastewater is considered one of the environmental problems. The large 28 quantity of these wastewaters is generated by various sources due to the rapid growth of 29 industrialization and urbanization over the past decades. Oils can enter the environment at different 30 stages of production, transportation, refining, and use (Zhu et al., 2018). The main sources of oil31 contaminated wastewater include food industries, oil refineries, petrochemical companies, and 32 metal, textiles, and leather producing plants, as well as restaurants, kitchens, and vehicles

33 (Mirshafiee et al., 2018). Discharge of oily effluent to the environment may cause irreparable 34 damages. Their very low solubility in water and very poor degradability cause detrimental effects 35 on the environment (Gurd et al., 2020). Layers of oil and grease can threaten aquatic life by 36 reducing oxygen and light penetration (Sharma et al., 2020). Oil, at higher levels, harms aquatic

37 life, creates obnoxious odors and unpleasant sights, reduces tourism activities, and causes 38 economic damage (Brillas et al., 2020). Various physical, chemical, and biological methods are 39 introduced for the removal of oil from wastewater, of which biological systems are significantly 40 used due to their advantages, of which more compatibility with the environment is noteworthy. 41 Moreover, no environmentally harmful chemicals are used in biological systems; therefore, their 42 effluent and sludge are less hazardous to the receiving waters than the chemical systems. These 
43 features make bioelectrochemical systems a cost-effective and environmental-friendly approach.

44 Biodegradation of organic matter is triggered by supporting microbial growth and creating 45 optimum environmental conditions to turn pollutants into carbon dioxide and other gases, 46 inorganic matter, water, safe and stable substances, and biomass. Among biological methods, 47 biofilm reactors have advantageous properties. It is well understood that biofilm reactors are 48 suitable for the treatment of effluents containing poorly biodegradable compounds and 49 decomposable organic matter. Biofilm, formed by the fixation on active microorganisms, increases 50 biomass and improves organic and hydraulic loading (Karadag et al.,2015). Fixed biofilm is 51 effective in reducing toxic compounds and the treatment of wastewater containing biodegradable 52 matter (Zhang et al., 2015). Other advantages of biofilm systems are longer shelf life, more diverse 53 microbial species, and increased stability(Tan et al., 2018). Numerous researchers tried to treat 54 oily effluent in anaerobic systems (Chan, et al., 2010; Wang et al., 2016). The anaerobic process, 55 widely used for industrial wastewater treatment, has advantages such as the generation of less 56 sludge, lower costs, less energy consumption, no need for aeration, low nutritional requirements, 57 high organic load tolerance, high shock loading resistance, and production of methane gas. The 58 improvement and repair of this process are faster if it is used in industries closed for a period in 59 the year with no utilization. It also has disadvantages as the quality of wastewater is not high and 60 does not meet the effluent disposal standards (Kong, et al., 2019). Therefore, an anaerobic system 61 needs further measures to be improved and upgraded, for example, increasing the activity of 62 bacteria by electrostimulation (Adibzadeh, et al., 2016). Bioelectrochemical systems (BESs) or 63 biofilm electrode reactors (BERs), as a relatively new technology, are appropriate and promising 64 methods with great potentials for wastewater treatment and are considered clean technology. In 65 this technology, microorganisms are used as an electrode-attached biofilm. In this method, 
oxidation-reduction (redox) reactions are catalyzed by the interaction between the electrode and

67 the biofilm. In recent years, wastewater treatment by BESs is critically considered by researchers(Cao, et al., 2018). Evidence suggests that induced current can stimulate metabolism

69 and enhance biochemical function in bacteria. The applied current increases the rate of ion 70 migration and reactions on the surface of the electrodes. Lower voltages are used in these systems,

71 which can overcome some problems such as corrosion of the anode and high energy consumption

72 observed in the electrochemical method. The induced current must be adequate, otherwise inverse 73 results are obtained, and the activity of microorganisms is restrained (Liu, et al., 2015). Due to the 74 increasing generation of oil-contaminated wastewater and the benefits of applying the anaerobic 75 method, and that this method needs upgrading and improvement of efficiency, the present study 76 aimed at investigating increased efficiency of anaerobic treatment of oil-contaminated wastewater

77 by electrostimulation and BESs. The main objectives of the present study were: (1) adaptation of 78 bacteria to BES under anaerobic conditions and determination of the effect of changes in the 79 applied electrical current on biomass performance by removal efficiency, (2) investigation of the 80 effect of operational parameters such as initial pollutant concentration, reaction time, and 81 supporting electrolyte, (3) improvement of the anaerobic process by BESs and comparison of the 82 removal efficiency of BES with a conventional method in the absence of applied current, (4) 83 estimation of energy consumed, and (5) kinetic study of the substrate removal process.

\section{2. Materials and methods}

\section{2.1. Experimental setup}

86 A cylindrical Plexiglas reactor, with an effective volume of $2.25 \mathrm{~L}$, was used in the present study.

87 It contained stainless steel electrodes fixed by a holder. It was covered to provide anaerobic 
88 conditions. The anode electrode was steel mesh, and its cavities were so small to facilitate the

89 loading of biomass. A magnetic stirrer (Alfa, HS-860, Iran) was used throughout the experiments

90 for gently mixing and homogenizing the reactor contents. Direct current was supplied by a power

91 supply (ATTEN APS3005S-3D, China). The electrodes were washed with HCl, rubbed with a

92 sponge, and rinsed with distilled water in order to be prepared.

93

94 Synthetic oil emulsions were prepared by adding edible oil and sodium dodecyl sulfate, as an 95 emulsifier, to distilled water and mixing for one hour at $900 \mathrm{rpm}$ (Mirshafiee et al., 2018).

\subsection{Wastewater preparation}

\subsection{Experimental procedure}

97 The current experimental, laboratory-scale study was performed as a batch system in a BER under anaerobic conditions. The seed sludge was taken from a wastewater treatment plant (Tehran, Iran), washed three times with tap water to remove impurities, and used as a microbial inoculant. All experiments were performed at ambient temperature $\left(25 \pm 2^{\circ} \mathrm{C}\right)$ and neutral $\mathrm{pH}$ range. Nutrients, added to enrich the bacteria, were composed of $\mathrm{NH}_{4} \mathrm{Cl} 0.50 \mathrm{~g} / \mathrm{L}, \mathrm{KH}_{2} \mathrm{PO} 40.25 \mathrm{~g} / \mathrm{L}, \mathrm{K}_{2} \mathrm{HPO}_{4} 0.25$ $\mathrm{g} / \mathrm{L}, \mathrm{MgCl}_{2} 0.30 \mathrm{~g} / \mathrm{L}, \mathrm{CoCl}_{2} 25 \mathrm{mg} / \mathrm{L}, \mathrm{ZnCl}_{2} 11.50 \mathrm{mg} / \mathrm{L}, \mathrm{CuCl}_{2} 10.50 \mathrm{mg} / \mathrm{L}, \mathrm{CaCl}_{2} 5 \mathrm{mg} / \mathrm{L}, \mathrm{MnCl}_{2}$ $15 \mathrm{mg} / \mathrm{L}, \mathrm{NiSO}_{4} 16 \mathrm{mg} / \mathrm{L}$, and $\mathrm{FeCl}_{3} 25 \mathrm{mg} / \mathrm{L}$. acclimatization of biomass, the effects of different operating parameters, such as changes in the applied current (5-30 mA), initial concentration of COD (1500 - $5000 \mathrm{mg} / \mathrm{L})$, reaction time (1-3

107 days) and supporting electrolyte (50-200 mg/L), were evaluated. In addition, the bacterial 108 community was investigated under optimal conditions, and the amount of energy consumed was 109 calculated. 
111 COD concentration was measured by the closed reflux method, described in the standard method.

112 The samples were analyzed using a spectrophotometer (Rayleigh, Vis-7220 / UV-9200). The

113 following equation was used to calculate the removal efficiency $(\operatorname{Re} \%)$ :

$$
\text { Removal Efficiency }=\frac{\mathrm{C} 0-\mathrm{Ct}}{\mathrm{C} 0} \times 100
$$

115 where $(\mathrm{C} 0)$ is the initial concentration $\left(\mathrm{mg} \cdot \mathrm{L}^{-1}\right)$ and $\left(\mathrm{C}_{\mathrm{t}}\right)$ the concentration at any time $\left(\mathrm{mg} \cdot \mathrm{L}^{-1}\right)$. A 116 portable $\mathrm{pH}$ meter (Oaklon, Malaysia) was used to measure the $\mathrm{pH}$. A scanning electron 117 microscopy (SEM, Seron technology, AIS-2100) was used to investigate the biofilm morphology.

\subsection{Kinetic modeling}

119 Kinetic models can be useful in the design and modeling of bioreactors, predict their performance, 120 determine the relationship between variables, and optimize the design. In the present study, three

121 common models of first-order, Grau model, and modified Stover-Kincannon were evaluated to 122 investigate the kinetics of the biological reactions.

\section{$123 \quad$ 2.5.1. First-order kinetic model}

124 Assuming that the first-order kinetic reactor is predominant, the changes in substrate concentration 125 in a completely-mixed system were expressed as follows:

$$
-\frac{\mathrm{ds}}{\mathrm{dt}}=\frac{\mathrm{Q} \mathrm{S}_{0}}{\mathrm{~V}}-\frac{\mathrm{Q} \mathrm{Se}}{\mathrm{V}}-\mathrm{K}_{1} \mathrm{Se}
$$

127 In a biological reactor, under steady-state conditions, changes in the removal of substrate 128 concentrations (-ds/dt) are negligible, so Equation 2 can be modified to Equation 3: 


$$
\frac{\mathrm{S}_{0}-\mathrm{Se}}{\mathrm{HRT}}=\mathrm{K}_{1} \mathrm{Se}
$$

130 where $S_{0}$ and $S_{e}$ are the substrate concentrations of influent and effluent $(\mathrm{mg} / \mathrm{L})$, Q the flow rate

131 of wastewater (L/d), V effective reactor volume (L), HRT hydraulic retention time (day), and K1

132 the first-order substrate removal rate constant $(1 / \mathrm{d})$.

133 The K1 can be obtained by plotting $\left[\left(\mathrm{S}_{0}-\mathrm{S}_{\mathrm{e}}\right) / \mathrm{HRT}\right]$ versus $\mathrm{S}_{\mathrm{e}}$. It can also be calculated based on the 134 slope of the line.

135 2.5.2. Grau model

136 The Grau model represents the second-order kinetics, which can be expressed by the following 137 equation:

$$
-\frac{\mathrm{ds}}{\mathrm{dt}}=\mathrm{K}_{2} \cdot X\left(\frac{\mathrm{Se}}{\mathrm{S}_{0}}\right)^{2}
$$

139 If Equation 4 is integrated and then linearized, Equation 5 is obtained as follows:

140

$$
\frac{\mathrm{S}_{0} \mathrm{HRT}}{\mathrm{S}_{0}-\mathrm{Se}}=\mathrm{HRT}-\frac{\mathrm{S}_{0}}{\mathrm{~K}_{2} \mathrm{X}}
$$

141 By holding the second part of the right side of Equation 5 as a constant value of a, Equation 6 is 142 obtained as follows:

$$
\frac{\mathrm{S}_{0} \mathrm{HRT}}{\mathrm{S}_{0}-\mathrm{Se}}=\mathrm{a}+\mathrm{bHRT}
$$

$144\left(\mathrm{~S}_{0}-\mathrm{S}_{\mathrm{e}}\right) / \mathrm{S}_{0}$ expresses the substrate removal efficiency and is symbolized as E. Therefore, the last 145 equation is as follows: 
147 where $a$ and $b$ are second-order kinetic constants, a $\mathrm{S}_{0} / \mathrm{K} 2 \mathrm{X}$, and $\mathrm{b}$ dimensionless.

148 The kinetic parameters of $\mathrm{a}$ and $\mathrm{b}$ can be determined by the intercept and slope of the plotline $\mathrm{S}_{0}$

$149 \mathrm{HRT} /\left(\mathrm{S}_{0}-\mathrm{S}_{\mathrm{e}}\right)$ versus HRT, respectively(Pahlavanzadeh et al., 2018).

151 Generally, the modified Stover-Kincannon model is widely used to evaluate the kinetic 152 parameters of biofilm reactors. This model is expressed as follows:

$$
\frac{\mathrm{dS}}{\mathrm{dt}}=\frac{\mathrm{Q}\left(\mathrm{S}_{0}-\mathrm{Se}\right)}{\mathrm{V}}=\frac{\mathrm{U}_{\max }\left(\frac{\mathrm{QS}_{0}}{\mathrm{~V}}\right)}{\mathrm{K}_{\mathrm{B}}+\left(\frac{\mathrm{QS}}{\mathrm{V}}\right)}
$$

154 where $K_{B}$ and $U_{\max }$ represent saturation constant (mg/L.day) and maximum substrate removal rate 155 (mg/L.day), respectively. The linear form of this equation is expressed as Equation 9:

156

$$
\left(\frac{\mathrm{dS}}{\mathrm{dt}}\right)^{-1}=\frac{\mathrm{V}}{\mathrm{Q}\left(\mathrm{S}_{0}-\mathrm{Se}\right)}=\frac{\mathrm{K}_{\mathrm{B}}}{\mathrm{U}_{\max }} \cdot\left(\frac{\mathrm{V}}{\mathrm{QS}_{0}}\right)+\frac{1}{\mathrm{U}_{\max }}
$$

157 Plotting V/[Q $\left.\left(\mathrm{S}_{0}-\mathrm{S}_{\mathrm{e}}\right)\right]$ versus $\left(\mathrm{V} / \mathrm{QS}_{0}\right)$ creates a straight line that gives the intercept and slope of 158 the line as $1 / \mathrm{U}_{\max }$ and $\mathrm{K}_{\mathrm{B}} / \mathrm{U}_{\max }$, respectively.

\section{Results and discussion}

\subsection{Start-up and biomass adaptation process}

161 Adaptation and acclimation is an important stage in the biological process. It is more sensitive in

162 the BESs since, in addition to pollutants and wastewater, the biomass should also be adapted to 
163 electric current. Oil-contaminated compounds usually contain substances that are not easily 164 degraded by bacteria in nature, so the bacteria should be acclimatized to the environment. The 165 gradual increase in pollutant concentration is a method that can be used for better adaptation. This 166 strategy prevents severe shocks, and by gradually adding oil-contaminated wastewater, the bacteria 167 are given the chance to adapt to the environment. Figure 1 shows the biomass adaptation results. 168 COD concentration at this stage was $1500 \mathrm{mg} / \mathrm{L}$, and HRT was considered three constant days. 169 Glucose was first used to acclimatize the bacteria to oil-contaminated wastewater as it is a palatable 170 organic matter for them. During the experiment, glucose levels were reduced and the oil171 contaminated wastewater was gradually added. On the other hand, since the electric current causes

172 bacterial lysis, a very low current was used in the adaptation stage in order to acclimatize them 173 over time. The induction current was $1 \mathrm{~mA}$ at this stage. The reactor was managed until reaching 174 stable conditions. The removal efficiency decreased to some extent after each increase in the 175 concentration of oil-contaminated wastewater, indicating that the system was shocked. The 176 bacteria then adapted to new conditions, and the system improved over time by continuing the 177 operation. The operation proceeded slowly until the entire influent was just the oil-contaminated 178 wastewater. The adaptation period lasted 105 days, and at the end of the start-up period, the 179 influent substrate was only the oil-contaminated wastewater.

\subsection{Effect of applied current}

181 Figure 2 shows the effect of the intensity of different applied currents on the bioelectrochemical 182 removal rate. In the present study, the current intensities of 5, 10, 15, 20, 25, and $30 \mathrm{~mA}$ were 183 investigated. Hydrolic retention time and initial COD concentration were considered constant. 184 Evaluation of the effect of changes in the applied current on the removal efficiency using BES 185 indicated that by applying a current intensity of $5 \mathrm{~mA}$, the removal efficiency was $72.3 \%$, and the 
applied current intensity increased after reaching stable conditions. With increasing current intensity above $15 \mathrm{~mA}$, the removal efficiency decreased, and the decreasing trend even continued by increasing the current intensity. In other words, a very high increase in current intensity reduced efficiency. As shown in Figure 2b, maximum efficiency was obtained at $15 \mathrm{~mA}$ that was $83.4 \%$. Therefore, it was selected as the optimum current and used in the experiment. The obtined results show that the optimum current has a beneficial effect on bacteria and their enzymatic activity. When an electric field is applied to the microbial system, the permeability of the cytoplasmic membrane increases, and as a result, nutrients better pass through the cell membrane. Increasing 194 the electrical field can also affect the activation of species carrying electrons. These species directly affect enzymes and promote bacterial metabolism. The activity and metabolism of most 196 microorganisms increase by electrostimulation or biostimulation (Zhang et al., 2014). 197 Electrostimulation of cells improves DNA and protein synthesis, cell membrane permeability, and 198 growth and can promote the biological removal of COD (Wei et al., 2011). Likewise, the direct 199 oxidation can affect the removal of contaminants, in which the organic matter is adsorbed on the surface of the anode and is removed (García-García et al., 2015). Over-optimum current intensities 201 have adverse effects on bacteria. High current intensity can cause direct oxidation in cell structure and death. In addition, it makes alterations in the permeability of the cell wall so that the molecules 203 diffuse to the outside (Adibzadeh, et al., 2016). High electric current can cause water electrolysis 204 and the generation of $\mathrm{H}_{2} \mathrm{O}_{2}$ and radicals, such as $\bullet \mathrm{OH}$ and $\bullet \mathrm{O}_{2}$, which are harmful and have a 205 detrimental effect on microbial metabolism, and ultimately inhibit microbial growth. Over206 optimum currents can cause irreversible permeability of cell membranes and subsequently lead to 207 leakage of essential cytoplasmic contents and lower cell respiration (Wei, et al. 2011). In the 208 indirect oxidation process, strong oxidants, such as hypochlorite/ chlorine, ozone, and hydrogen 
209 peroxide, are produced based on electrochemical reactions. All these oxidants are produced in situ

210 and used immediately; they can also be harmful to the biofilm in higher concentrations (García-

211 García et al., 2015). Zhang et al., (2011) studied BER, in which microorganisms specifically attach

212 to the electrode as a biofilm and play a pivotal role in biodegradation. They reported that applying

213 over-optimum currents causes separation and fall-off microorganisms from the electrode (Zhang

214 et al., 2011).

\section{3.3. Effect of the initial concentration of COD}

216 Change in influent concentration is one of the factors affecting biological treatment processes.

217 After determining the optimum current intensity, the efficacy of the bioreactor in the removal of

218 influent was evaluated at different concentrations. Figure 3 shows the removal efficacy of BER at

219 different COD concentrations. According to Figure 3, after increasing the COD concentration, the

220 system efficacy decreased due to the shock caused by the applied concentration, and a few days

221 later, the efficiency gradually increased and approached the previous state. When the system

222 stabilized, the influent concentration was suddenly increased. When the reactor faced an organic

223 shock loading, the biomass tried gradually be adapted to it to regenerate the system; however, at

224 higher concentrations, the improvement remained incomplete as, under stable conditions and high

225 concentrations, the removal efficiency decreased. The average removal efficiency of oil-

226 contaminated wastewater by bioelectrochemical method at different initial concentrations is shown

227 in Figure 3b. The maximum COD removal efficiency was obtained at $1500 \mathrm{mg} / \mathrm{L}$. With further

228 increase in the influent concentration, shock loadings imposed on the bioreactor increased so that

229 the average removal efficiency decreased with concentration increase. The results showed that

230 increased concentrations exceeded the maximum biodegradation capacity of microorganisms and

231 played a limiting role in biomass. Therefore, to prevent biomass loss, continue the experiment, and 
232 investigate the effect of retention time on process efficiency, the influent concentration returned

233 to the baseline state $(1500 \mathrm{mg} / \mathrm{L})$. Different concentrations can directly affect the biomass activity

234 and ohmic resistance of BES. The reason for a decrease in removal efficiency with an increase in

235 influent concentration may be due to the point that higher oil-contaminated wastewater as substrate

236 concentrations can act as a limiting factor on the biofilm (Mudliar et al., 2008). High

237 concentrations create a critical state in microorganisms. With an increase in initial concentration,

238 the time required to achieve the latest removal efficiency also increases. Therefore, with an

239 increase in concentration, bacteria need more time for degradation. Wen et al. (2013), in a study

240 on BES, reported that at the reaction time of 24 hours, under the same conditions, the removal

241 efficiency of the system decreased from $82.3 \%$ to $50.3 \%$ with increasing the initial concentration

242 of pollutants from 0.19 to $0.78 \mathrm{mM}$ (Wena et al. 2013). Xuena et al., (2009) concluded that in

243 BESs, increasing the concentration of influent can inhibit the growth of bacteria on biofilm (Xuena

244 et al., 2009).

\subsection{Effect of hydrolic retention time}

246 The reaction time is one of the major parameters in BESs. After examining different concentrations

247 and applying organic shock loading, the COD concentration was set again at $1500 \mathrm{mg} / \mathrm{L}$, and when

248 the system stabilized, the effect of hydrolic retention time (HRT) changes on the optimal current 249 intensity was investigated. At this stage, HRT was reduced step by step while the concentration 250 was constant. As shown in Figure 4, HRT was studied at different reaction times of 1, 1.5, 2, 2.5, 251 and 3 days. Changes in reaction time increased organic loads. As shown in Figure 4a, the efficiency 252 decreased with decreasing reaction time from 3 to 2.5 days. However, the bioreactor efficiency 253 improved somewhat over time, although it did not reach the initial state. As soon as the system 254 stabilized, the retention time was reduced again from 2.5 to 2 days, in which an immediate decrease 
was observed in efficiency, but improved over time, although it did not reach the initial state. The greater reduction in retention time, the greater reduction in efficiency. Figure $4 \mathrm{~b}$ shows the average removal efficiency of COD by BES after reaching stable conditions at different time points. It can

258 be concluded that time reduction adversely affects COD removal efficiency. The maximum 259 efficiency was $84.2 \%$ in the best conditions in terms of reaction time. Organic loading increases 260 with a reduction in HRT. Therefore, it can be concluded that the removal efficiency increases at 261 higher HRTs, which is proportional to the lower load on the system. Investigation of residuals in 262 the system showed that the residual COD increased with decreasing reaction time in BES. The 263 reason for decreased efficiency versus reduced time is mainly related to reduced contact time 264 between the substrate and biomass, which does not provide sufficient time for conveying the 265 materials of liquid mass to biomass. As a result, the COD concentration increases in the effluent, 266 and the removal efficiency decreases. In other words, a shorter contact time between biomass and 267 oil-contaminated wastewater reduces biodegradation. In addition, a decrease in efficiency due to 268 a reduction in retention time results from the fact that, despite a constant concentration of the 269 substrate, microorganisms encounter an increase in organic load (Dareioti et al., 2014). 270 Mohanakrishna et al., (2018) conducted a study on the treatment of oil-contaminated wastewater 271 in an oil refinery by BES. They utilized a reactor with an effective volume of $1.13 \mathrm{~L}$ and two $2725 \times 5 \times 1-\mathrm{cm}$ electrodes. Four different HRTs were considered in the study, and they concluded that 273 the conditions for electrostimulation are more suitable at higher HRTs than shorter times in BESs. 274 That is, the removal efficiency is higher at higher HRTs. They also found that the oil and grease 275 removal efficiencies were significantly higher than that of COD, which could be due to the 276 degradation of oil complex molecules into simpler ones still occurring as total COD ( 277 Mohanakrishna et al., 2018). Zhuang et al. (2014), in a study on biological treatment of wastewater, 
278 concluded that as the retention time decreases, the efficiency of denitrification decreases, and the 279 reason can be attributed to insufficient contact time between biomass and substrate, as well as the 280 separation of biofilm from media and its wash-out (Zhuang et al., 2014). Guo et al. (2017), in a 281 study on the effect of HRT on denitrification performance, indicated that the critical point of HRT 282 effect on microbial process performance is the provision of contact time between biomass and 283 substrate for microbial reaction. With an increase in retention time (within a particular range), the 284 removal efficiency also increases. This increase in time leads to sufficient contact time between 285 bacteria and wastewater. Sufficient contact time between the microbial population and substrate is 286 not provided at shorter retention times for complete degradation, which leads to a reduction in 287 removal efficiency. In addition, HRT can affect the secretion of extracellular polymeric substances 288 (EPS) and the activity and accumulation of microorganisms. These materials also have a protective 289 effect; they hold the biofilm-forming bacteria together and protect them against toxins and sudden 290 increase in concentration to prevent them from wash-out (Guo, et al., 2017). HRT is a key 291 parameter in BERs. Increased retention time persuades bacteria to excessively consume and 292 degrade organic matter. It can also affect the type of microbial population. The longer retention 293 time helps bacteria to more acclimatize to biodegradation-resistant and toxic substances. They can 294 repair their enzyme system to acclimatize to these compounds or biodegrade them. Large bacterial 295 populations may also develop enzyme systems suitable for degrading such organic matters. 296 Therefore, researchers believe that higher HRTs are beneficial for the removal of poorly 297 degradable or biodegradation-resistant compounds. In a bioreactor that refines poorly-degradable 298 materials, a longer HRT can help to achieve high biodegradation efficiencies. Increased HRT gives 299 more chance to substances to better contact microorganisms that increases the biodegradation rate. 300 In lower HRTs, organic loading increases, leading to incomplete biodegradation so that the 
301 degradation process remains incomplete. In addition to influencing the efficiency of the process, 302 HRT affects reactor volume and manufacturing costs. Therefore, determining the optimum time 303 for an acceptable and satisfactory efficiency is one of the main stages in the bioreactor design, 304 considering the minimum bioreactor volume required (Shi et al., 2017). To prevent the loss of 305 system biomass, resulting from shock loading, and improve the reactor performance, HRT 306 increased at the initial stage (three days).

\section{3.5. Effect of supporting electrolyte}

308 Considering a relatively high solubility, availability, low cost, and less toxicity, $\mathrm{NaCl}$ was used in 309 the present study as a supporting electrolyte. The effect of $\mathrm{NaCl}$ at different concentrations of 50, 310100,150 , and $200 \mathrm{mg} / \mathrm{L}$ was investigated, and the results are shown in Figure 5. According to 311 Figure 5, by increasing $\mathrm{NaCl}$ concentration from 50 to $100 \mathrm{mg} / \mathrm{L}$, the efficiency slightly increased 312 and the trend continued by increasing to $150 \mathrm{mg} / \mathrm{L}$. When the system stabilized, the $\mathrm{NaCl}$ 313 concentration was increased to $200 \mathrm{mg} / \mathrm{L}$, along which the efficiency decreased as the bioreactor 314 was shocked. The removal efficiency somewhat improved by continuing the system exploitation 315 in the next days but did not return to the initial state even after the system stabilization. According 316 to the results, a threshold could be considered for the system biomass. As shown in Figure 5b, the 317 highest removal efficiency was $86.7 \%$ at $150 \mathrm{mg} / \mathrm{L}$. When concentration increases, the system 318 bacteria are shocked, and the efficiency decreases.

319 Solution resistance $(\mathrm{R})$ can be calculated using Ohm's law as Equation 10:

$$
\eta_{\mathrm{ohm}}=\mathrm{IR}
$$

321 where $\eta_{\mathrm{ohm}}$ is ohmic overpotential (V), I current intensity (A), and R the local resistance of the 322 electrochemical cell (ohm). 
323 Also, the resistance of the solution can be calculated using Equation 11:

$$
\mathrm{R}=\rho \frac{\mathrm{d}}{\mathrm{A}}
$$

325 Accordingly, Equation 10 would be:

$$
\eta_{\mathrm{ohm}}=\rho \frac{\mathrm{d}}{\mathrm{A}} \mathrm{I}
$$

327 where $\rho$ is the electrical resistivity $(\Omega \mathrm{m})$ and the electrical conductivity $(\sigma)$ is its inverse, $d$ the 328 distance between the anode and the cathode $(\mathrm{m})$, and A the surface area between the anode and the 329 cathode $\left(\mathrm{m}^{2}\right)$. One of the features of electrochemical and bioelectrochemical systems is that with 330 an increase in the $\mathrm{NaCl}$ concentration and increase in the ionic conductivity of the solution, the 331 ohmic resistance of the electrochemical cell reduces significantly, leading to improved efficiency. 332 Considering equations 10 and 12, an increase in supporting electrolyte reduces energy 333 consumption. Therefore, the presence of $\mathrm{NaCl}$ in the solution is economically advantageous over 334 the electrochemical process and reduces costs. Increased $\mathrm{NaCl}$ concentration in the solutions of 335 electrochemical and bioelectrochemical systems facilitates the electric current and reduces energy 336 consumption. Likewise, many researchers suggested the addition of $\mathrm{NaCl}$ to increase electrical 337 conductivity in such systems (Alam et al., 2016). Kokabian et al., (2013) stated that the effect of $338 \mathrm{NaCl}$ on the performance of anaerobic treatment systems depends on the nature of the microbial 339 population. The study results showed that with increasing salinity, the removal efficiency of 340 anaerobic bacteria increased initially but reduced with a further increase (exceeding the 341 recommended threshold) due to its adverse effects on the system (Kokabian et al., 2013). Aslan et 342 al. (2012), in a study entitled "The Influence of Salinity on Partial Nitrification in a Submerged 343 Biofilter", concluded that with adding $\mathrm{NaCl}$, the removal efficacy increased initially but reduced 
with further increase. Different studies reported the stimulation of various bacterial species in low salinity. Although the low salinity of influent stimulates bacteria and increases their activity, higher concentrations act inversely. The effect of shock loading is evident at higher salt concentrations. High salinity causes plasmolysis and decreased bacterial activity. The susceptibility of microorganisms to salinity- e g, bacterial tolerance to $\mathrm{NaCl}$ - is not the same, and some bacteria are less sensitive than others. Even laboratory conditions, such as $\mathrm{pH}$, temperature, solid retention time (SRT), HRT, and suspended or attached growth system, can affect bacterial strains' susceptibility to salinity (Aslan et al., 2012). Lefebvre et al., (2012) concluded that salinity is generally useful for power production in the microbial fuel cell (MFC) process because an increase in ionic conductivity improves proton transfer and reduces the internal resistance of the system. However, excess salinity has inverse consequences on the physiology of the anaerobic microbial consortia (Lefebvre et al., 2012). Electrolyte and electrode ohmic losses are the two major types of ohmic resistance in BESs. The first one represents the voltage drop due to the movement of ions through weak electrolytes (usually low-conductivity wastewater), and the second refers to the movement of electrons through electrodes and wires connected to them. Many real wastewaters encounter significant ohmic losses since their conductivity is low. Therefore, in the treatment of wastewaters with ohmic resistance, approaches to overcome this dilemma should be considered.To overcome the ohmic resistance, first, it is recommended to reduce the distance between the electrodes as much as possible; however, it is impossible in most cases. Second, increase the conductivity or ionic strength by adding the required amounts of $\mathrm{NaCl}$ to the solution (Rozendal et al., 2008). Gui et al. (2017), in a study on the effect of $\mathrm{NaCl}$ on the denitrification process, indicated different effects of salinity across various concentrations and its inhibitory and toxic role in concentrations exceeding threshold limits. The toxicity of $\mathrm{NaCl}$ in low salinity is related to the hindrance of the 
enzymatic activity of denitrifiers; in high salinity, however, in addition to the mentioned reason, it is also related to bacterial death (Gui et al., 2017). Ahmadi et al. (2017), in a study on the treatment of petrochemical wastewater by a salt-tolerant bacterial consortium, investigated the effect of salinity and determined the threshold under an HRT of three days and the initial COD concentration of $1240 \mathrm{mg} / \mathrm{L}$. The results showed that salinity above the threshold caused a sharp and sudden decrease in COD removal efficiency, which is related to the loss and death of biomass due to the harmful effects of high salinity on the enzymatic activity of bacteria and their plasmolysis. At this time, the turbidity and TSS of the effluent increase significantly due to bacterial death and minimal biomass deposition (Ahmadi et al., 2017). The survival of the microbial population usually depends on adequate osmotic pressure in the environment. The concentration of the solution is correlated with the osmotic pressure so that if the mineral salt concentration is high in a solution, the osmotic pressure increases. Under isotonic conditions (e g, 0.85 wt. $\% \mathrm{NaCl}$ ), microbial metabolism and growth are optimum. Since water molecules penetrate microorganisms, they may swell and even burst in pure or low salinity waters (e g, 0.01 wt.\% $\mathrm{NaCl})$. But bacterial plasmolysis occurs in environments with very high salinity (e g, 2 wt.\% of $\mathrm{NaCl}$ ) because water molecules diffuse to the outside, hindering microbial growth and even causing death. At this time, the concentration of suspended solids increases in the effluent due to microbial death. If salinity increases slowly in the system, the bacteria can reduce its adverse effects and acclimatize to the environment as much as possible. The reason may be that bacteria can regulate osmotic pressure by the efflux pump mechanism (e g, contractile vacuole) or synthesis of compatible salts when salinity increases. The higher salinity leads to more energy consumption by bacteria to maintain osmotic pressure. As a result, the energy accessible to microbial synthesis and function reduces. Microorganisms need organic matter for growth, the process performed 
with the contribution of enzymes. Microbial enzymes are sensitive to toxins as they are typically proteins. If wastewaters contain some toxic substances, the enzymes are inactivated, and as a result,

392 the removal efficiency of wastewater treatment reduces. The right amount of mineral salts

393 improves microbial metabolism, but exerts toxic effects in excessive amounts, reduces the activity

394 of enzymes, and destructs them. However, the bacteria probably can trigger a new enzyme system

395 in the saline environment that helps to acclimatize to the new environment (He et al.,2017). Indirect

396 oxidation at the anode is also one of the reactions happening during electrochemical and

397 bioelectrochemical processes in the presence of chlorine ions. In indirect oxidation, strong 398 oxidants, such as hypochlorite/chlorine, hydrogen peroxide, and ozone are generated by 399 electrochemical reactions. All these oxidants in high concentrators are harmful to the biofilm. 400 Indirect reactions of chlorine can be triggered by $\mathrm{NaCl}$ decomposition, based on the following 401 equations, and its overproduction can cause microbial death.

402 These reactions occur when chlorine ions are the structural component of the salts used.

$$
2 \mathrm{Cl}^{-} \rightarrow \mathrm{Cl}_{2}+2 \mathrm{e}^{-}
$$

$$
\mathrm{Cl}_{2}+\mathrm{H}_{2} \mathrm{O} \rightarrow \mathrm{HOCl}+\mathrm{H}^{+}+\mathrm{Cl}^{-}
$$

$$
\mathrm{HOCl} \leftrightarrow \mathrm{ClO}^{-}+\mathrm{H}^{+}
$$

406 In addition to $\mathrm{ClO}^{-}$, side reactions generate $\mathrm{ClO}_{2}^{-}, \mathrm{ClO}_{3}^{-}$, and $\mathrm{ClO}_{4}^{-}$through anodic oxidation, 407 which can be hazardous to bacteria in high concentrations (Bassyouni et al., 2017).

409 Today, various methods are employed to identify biofilms, one of which is microscopic examination. In this method, magnified images are taken from the specimen. The SEM was utilized 
411 in the present study to investigate the bacterial community of the biofilm. According to Figure 6,

412 the predominant bacteria in the bioreactor were rod-shaped (bacilli) and cocci. The biofilm

413 includes a bacterial consortium and is composed of a dense bacterial population. In terms of

414 structure, the biofilm has channels allowing the transfer of substrates to the inner part for bacterial

415 accessibility. The results of the present study were consistent with those of Luo et al. (2005). It was

416 reported that at the optimum current intensity, the biofilm-holding bacteria were rod-shaped and

417 cocci, which their natural shape might be changed at different current intensities (Luo et al.,, 2005).

418 Figure 6 illustrates the presence of EPS secretions between bacteria. A biofilm is a community of 419 bacteria attached to a surface and covered by EPSs. Huang et al., (2013) concluded in a study that 420 an increase in electric current can trigger EPS efflux, which ultimately leads to the better formation 421 of biofilm in BES. However, the microbial activity varies across electric currents. The biofilm 422 formation in a BES is of great importance for the removal of pollutants or the production of electric 423 current. They found that at optimum current intensities, the biofilm formation is promoted and 424 improves. However, when the current intensity exceeds the optimum level affects the biofilm 425 adversely and diminishes its formation. They also concluded that the biofilm in BESs nurtured 426 with organic matter is better formed near the anode than the cathode. They reported that EPSs are 427 essential for biofilm formation. Their structural composition depends on the growing conditions 428 of the biofilm. EPSs are composed of polysaccharides, proteins, nucleic acids, and DNAs; 429 however, they are mostly constructed from proteins and carbohydrates. Studies on the composition 430 of EPSs led to a variety of results. Some studies concluded that polysaccharides predominate in 431 the EPS layer of biofilms, while others reported proteins as the main constituent. These 432 contradictory findings indicate that the composition of biofilms depends on growth conditions. In 433 the study by Huang, with excessing the optimum electric current, the EPS also increased and 
434 decreased with a further increase, which disrupted the formation of biofilms and inhibited 435 microbial growth (Huang et al.,, 2013). Some cavities and channels seen in Figure 6 are related to 436 the inlet of nutrients and outlet of substances generated by bacteria; they allow substrates to 437 transfer through the inner part of the biofilm (Muda et al., 2010). The results of Gram staining are 438 shown in Figure 6b. According to Figure 6b, the effluent was treated with a consortium, including 439 Gram-positive and -negative bacteria. Simmilarly, Poh et al. (2010), in a study on the treatment of 440 palm oil mill effluent by an anaerobic method, reported that most bacteria detected in the 441 consortium were rod-shaped and cocci, and Gram staining proved that both Gram-positive and 442 negative species were involved in the process (Poh et al.,, 2010).

444 An experiment was performed to evaluate the effect of induction and electrostimulation on the 445 removal efficiency of COD. It was performed under the same conditions. Accordingly, BES was 446 compared with a similar bioreactor in the absence of DC (Figure 7). The removal efficiency at the 447 biological state without DC was $65.9 \%$, but it was $86.7 \%$ at the BES state. Based on the obtained 448 results, the electric current could positively affect BES, leading to higher removal efficiency than 449 other reactors since it stimulates bacterial growth. In the electrostimulation or biostimulation 450 process, enzymatic activity, cellular biopolymers synthesis, membrane transfers, and reproduction 451 are influenced by the process and can improve the removal efficiency. Cardenas-Robles et al. 452 (2013), in a study on azo dye degradation by BES, concluded that the application of 453 electrostimulation increases the dye removal efficiency. The results also showed that 454 electrostimulation, in addition to an increase in efficiency, reduces the time required for the 455 complete removal of pollutants. This reduction in time also decreases the reactor volume, which 456 leads to the lower design and implementation costs (Cardenas-Robles et al., 2013). 
457 Zhang et al. (2011), in a study on the degradation of 2,4-dichlorophenol by BES in an anaerobic 458 process, reported good results and high efficiency. They compared the removal efficiency of BES 459 and biological (in the absence of electric current) and electrochemistry methods and showed that 460 the bioelectrode process had higher efficiency than the other two methods, and the removal 461 efficiency of pollutants was lower in pure biological and pure electrochemical processes. The 462 removal efficiency of the investigated processes was $100 \%, 42 \%$, and $61 \%$, respectively. This 463 improvement and increase in removal efficiency were due to the electrostimulation of bacteria 464 (Zhang et al., 2011).

465 3.8. Kinetic study

466 3.8.1. First-order kinetic model

467 The steady-state data of each stage were used to determine the kinetic coefficients. As shown in 468 Figure 10a and Table 1, the first-order kinetic constant (K1) was 0.485 (1/d). Also, the correlation 469 coefficient $\left(\mathrm{R}^{2}\right)$ was 0.85 .

\section{$470 \quad$ 3.8.2. Second-order kinetic model (Grau model)}

471 The $\mathrm{R}^{2}$ for the second-order kinetic model was 0.961 , indicating that the COD removal process 472 could also follow the second-order model (Figure 8). The kinetic constants of a and b were 1.338

473 and 0.694 day $^{-1}$, respectively. Besides, increasing a or b parameters had a direct and adverse effect 474 on efficiency, the removal efficiency increased in the system.

475 3.8.3. Modified Stover-Kincannon model

476 In the present study, $\mathrm{U}_{\max }$ was 1.106 and $\mathrm{K}_{\mathrm{B}} 0.767 \mathrm{~g} / \mathrm{L} . \mathrm{d}$. Both $\mathrm{KB}$ and $\mathrm{U}_{\max }$ play a pivotal role in 477 determining the volume of a bioreactor. The results showed that among the three proposed models, 
478 the $\mathrm{R}^{2}$ of the modified Stover-Kincannon model was higher (0.975), indicating that the model was

479 more fitted with bioreactor performance and the COD removal reaction was more consistent with

480 it. Therefore, the modified Stover-Kincannon model can be used for the accurate prediction of the

481 removal of biodegradable organic matter.

482

\section{3-9- Energy consumption}

483 Cost is one of the most important factors in choosing water and wastewater treatment methods.

484 The consumed energy plays a particular role in the costs of electrochemical processes. Therefore,

485 energy consumption was calculated using the following equation:

$$
\mathrm{E}\left(\frac{\mathrm{Kwh}}{\mathrm{m} 3}\right)=\frac{\mathrm{U} \times \mathrm{I} \times \mathrm{t}}{\mathrm{V}}
$$

487 where $\mathrm{U}$ is the applied voltage $(\mathrm{V}), \mathrm{I}$ the current intensity $(\mathrm{A}), \mathrm{t}$ the reaction time $(\mathrm{h})$, and $\mathrm{V}$ the 488 volume of the effluent (L). According to the applied optimum current intensity (15 mA) and 489 reaction time (three days), the amount of energy consumed by BES was $1.9145 \mathrm{kWh} / \mathrm{m}^{3}$. The 490 electrochemical process was used to obtain the same removal efficiency, which according to the 491 applied current intensity ( 1 A) and reaction time ( 2 hours), the energy consumed by the 492 electrochemical process was $45.33 \mathrm{kWh} / \mathrm{m}^{3}$. The comparison of the above results indicated that 493 the cost of energy consumed by BES was much lower than that of the electrochemical system. In 494 addition, the cost of electrodes was another factor affecting the cost, which considering higher 495 current intensity and voltage in the electrochemical method, corrosion and consumption rate of 496 electrodes was higher in this method than BES. Jinyou Shen et al., (2012) reported similar results 497 in a study on BES. They concluded that the cost of energy consumed by the BES was much lower 498 than that of the electrochemical one. Excessive energy consumption, as an important drawback, 499 limits the use of the electrochemical system on a large scale. BESs can be used to reduce energy 
500 consumption in the electrochemical method, which significantly reduces energy consumption in

501 the system compared to other ones (Shen et al., 2012). Wen et al., (2013) investigated the

502 degradation of 4-chlorophenol by BES in an anaerobic process. They estimated that the energy

503 consumed by BES was 5 to 30 times lower than that of the electrochemical one. They concluded

504 that this technology would be a method of choice for the removal of many pollutants due to its

505 higher efficiency and lower energy consumption (Wena et al., 2013).

\section{4. Conclusions}

507 In the present study, BERs were used to treat oil-contaminated wastewater. The results showed 508 that this process could be very advantageous for the treatment of such wastewaters. The study also 509 confirmed that BERs have higher efficiencies than pure electrochemical ones under the same 510 conditions, indicating that electrostimulation under optimal conditions can increase removal 511 efficiency. However, if the current intensity exceeds optimal levels, the biofilm biomass is lost, 512 and thus the removal efficiency decreases. The results showed that the removal of biodegradable 513 organic matter could accurately be predicted by the modified Stover-Kincannon model. Based on 514 the findings, the cost of energy consumed by BERs was much lower than that of the 515 electrochemical one. The study also indicated that BERs are a promising method with good 516 prospects for the treatment of oil-contaminated wastewaters.

517 Authors' contributions: A. Mirshafiee performed experiments, analyzed data and co-wrote the 518 paper; A. Rezaee designed experiments and supervised the research.

519 Funding: This study was supported by TarbiatModares University, Ph.D. thesis support.

520 Data availability: All data generated or analyzed during this study are included in this published 521 article. 
522 Compliance with ethical standards: Competing interests The authors declare that they have no 523 conflict of interest.

524 Ethics approval and consent to participate: This research did not involve any human 525 participants and/or animals.

526 Consent for publication: The authors accepted the publication.

\section{References}

528 Adibzadeh A, Rezaee A, Salehi Z (2016) Enhancement of lipase activity for the oily wastewater 529 treatment by an electrostimulation process. RSC Adv 6: 115290-115297.

530 Ahmadi M, Jorfi S, Kujlu R, Ghafari S, Darvishi Cheshmeh Soltani R, Jaafarzadeh Haghighifard 531 N (2017) A novel salt-tolerant bacterial consortium for biodegradation of saline and 532 533 534 recalcitrant petrochemical wastewater. J Environ Manag 191: 198-208.

Alam R, Shang JQ (2016) Electrochemical model of electro-flotation. J. Water Process Eng 12: 78-88.

Aslan S, Simsek E (2012) Influence of salinity on partial nitrification in a submerged biofilter. Bioresource Technol 118: 24-29.

Bassyouni DG, Hamed HA, El-Ashtoukhy E-S.Z, Amin NK, Abd El-Latif, MM (2017)

541 Brillas E (2020) A review on the photoelectro-Fenton process as efficient electrochemical 542 advanced oxidation for wastewater remediation. Treatment with UV light, sunlight, and 
coupling with conventional and other photo-assisted advanced technologies. Chemosphere 250: $120198-120204$.

Cao X, Wang H, Zhang S, Nishimura O, Li X (2018) Azo dye degradation pathway and bacterial community structure in biofilm electrode reactors. Chemosphere 208: 219-225.

Cardenas-Robles A, Martinez E, Rendon-Alcantar I, Frontana C, Gonzalez-Gutierrez L (2013) Development of an activated carbon-packed microbial bioelectrochemical system for azo dye degradation. Bioresource Technol 127: 37-43.

Chan YJ, Chong M.F, Law CL (2010) Biological treatment of anaerobically digested palm oil mill effluent (POME) using a Lab-Scale Sequencing Batch Reactor (SBR), J Environ Manag 91: 1738-1746.

García-García, A, Martines-Miranda V, Martínez-Cienfuegos IG, Almazán-Sánchez PT, Castañeda-Juárez M, Linares-Hernández I (2015) Industrial wastewater treatment by electrocoagulation-electrooxidation processes powered by solar cells. Fuel 149: 46-54.

Gui M, Chen Q, Ni J (2017) Effect of $\mathrm{NaCl}$ on aerobic denitrification by strain Achromobacter sp. GAD-3. Appl Microbiol Biotechnol 101: 5139-5147.

Guo Y, Guo L, Sun M, Zhao Y, Gao M, She Z (2017) Effects of hydraulic retention time (HRT) on denitrification using waste activated sludge thermal hydrolysis liquid and acidogenic liquid as carbon sources. Bioresource Technol 224: 147-156.

Gurd C, Villa R, Jefferson B (2020) Understanding why fat, oil and grease (FOG) bioremediation can be unsuccessful, J Environ Manage 267: 110647-110657.

He H, Chen Y, Li X, Cheng Y, Yang C, Zeng G (2017) Influence of salinity on microorganisms in activated sludge processes: A review. Int Biodeterioration Biodegradation 119: 520-527. 
Huang B, Feng H, Ding Y, Zheng X, Wang M, Li N, Shen D, Zhang H (2013) Microbial metabolism and activity in terms of nitrate removal in bioelectrochemical systems. Electrochimica Acta 113: 29-36.

Karadag D, Koroglu OE, Ozkaya B, Cakmaki M (2015) A review on anaerobic biofilm reactors for the treatment of dairy industry wastewater. Process Biochem 50: 262-171.

Kokabian B, Bonakdarpour B, Fazel S (2013) The effect of salt on the performance and characteristics of a combined anaerobic-aerobic biological process for the treatment of synthetic wastewaters containing Reactive Black 5. Chem Eng J 221: 363-372.

Kong Z, Li L, Xu Y, Yang M, Li Y (2019) Challenges and prospects for the anaerobic treatment of chemical-industrial organic wastewater: A review, J Clean Product 231: 913-927.

Lefebvre O, Tan Z, Kharkwal S, Ng HY (2012) Effect of increasing anodic NaCl concentration on microbial fuel cell performance. Bioresource Technol 112: 336-340.

Liu H, Tong S, Chen N, Liu Y, Feng C, Hu Q (2015) Effect of electro-stimulation on activity of heterotrophic denitrifying bacteria and denitrification performance. Bioresource Technol 196: $123-128$.

Luo Q, Wang H, Zhang X, Qian Y (2005) Effect of Direct Electric Current on the Cell Surface Properties of Phenol-Degrading Bacteria. Appl Environ Microbiol 423-427.

Mirshafiee A, Rezaee A, Sarraf Mamoory R (2018) A clean production process for edible oil removal from wastewater using an electroflotation with horizontal arrangement of mesh electrodes. J Clean Product 198: 71-79.

Mohanakrishna G, Al-Raoush RI, Abu-Reesh. I (2018) Induced bioelectrochemical metabolism for bioremediation of petroleum refinery wastewater: Optimization of applied potential and flow of wastewater. Bioresource Technol 260: 227-232. 
602

603

604

605

606

607

608

609

610

Muda K, Aris A, Salim MR, Ibrahim Z,Yahya A, Loosdrecht MCV, Ahmad A, Nawahwi MZ (2010) Development of granular sludge for textile wastewater treatment. Water Res 44: 4341-4350.

Mudliar SN, Padoley KV, Bhatt P, Sureshkumar M, Lokhande SK, Pandey R.A, Vaidya AN(2008) Pyridine biodegradation in a novel rotating rope bioreactor. Bioresource Technol 99: 1044-1051.

Pahlavanzadeh S, Zoroufchibenis K, Shakerkhatibi M, Karimi Jashni A, Taleb Beydokhti N, Alizadeh Kordkandi S (2018) Performance and kinetic modeling of an aerated submerged fixed-film bioreactor for BOD and nitrogen removal from municipal wastewater. J Environ Chem Eng 6: 6154-6164.

Poh PE, Chong M.F (2010) Biomethanation of Palm Oil Mill Effluent (POME) with a thermophilic mixed culture cultivated using POME as a substrate. Chem Eng J 164: 146-154.

Rozendal RA, Hamelers HVM, Rabaey K, Keller J, Buisman CJN (2008) Towards practical implementation of bioelectrochemical wastewater treatment. Trends in Biotechnology 26: 450-459.

Sharma S, Aygun A, Simsek H (2020) Electrochemical treatment of sunflower oil refinery wastewater and optimization of the parameters using response surface methodology, Chemosphere 249: 126511-126520.

Shi Y, Huang C, Gamal El-Din M, Liu Y (2017) Optimization of moving bed biofilm reactors for oil sands process-affected water treatment: The effect of HRT and ammonia concentrations. Sci Total Environ 598: 690-696.

Shen J, Feng C, Zhang Y, Jia F, Sun X, Li J, Han W, Wang, L, Mu Y (2012) Bioelectrochemical system for recalcitrant p-nitrophenol removal. J Hazard Mater 209:210, 516-519. 
Tan C, Xu H, Cui D, Zuo J, Li J, Ji Y, Qiu S, Yao L, Chen Y, Liu Y (2018) Effects of tourmaline on nitrogen removal performance and biofilm structures in the sequencing batch biofilm reactor. J Environ Sci 67: 127-135.

Wang Y, Wang Q, Li M, Yang Y, He W, Yan G, Guo S (2016) An alternative anaerobic treatment process for treatment of heavy oil refinery wastewater containing polar organics. Biochem Eng J (105) 44-51.

Wei , Elektorowicz, M., Oleszkiewicz, J.A., 2011. Influence of electric current on bacterial viability in wastewater treatment. Water Res 45: 5058-5062.

Wena Q, Yang T, Wang S, Chen Y, Cong L, Qu Y (2013) Dechlorination of 4-chlorophenol to phenol in bioelectrochemical systems. J Hazad Mater 244-245: 743-749.

Xuena Z, Huang W, Xuan W, Yu G, Haibo L (2009) Feasibility and advantage of biofilm-electrode reactor for phenol degradation. J Environ Sci 21: 1181-1185.

Zhang X-N, Huang W-M, Wang X, Li H, Lu HY, Lin H-B (2011) Biofilm-electrode process with high efficiency for degradation of 2,4-dichlorophenol. Environ Chem Lett 9: 383-388.

Zhang B, Liu Y, Tong S, Zheng M, Zhao Y, Tian C, Liu H, Feng C (2014) Enhancement of bacterial denitrification for nitrate removal in groundwater with electrical stimulation from microbial fuel cells. J Power Sources 268: 423-429.

Zhuang H, Han H, Jia S, Zhao Q, Hou, B (2014) Advanced treatment of biologically pretreated coal gasification wastewater using a novel anoxic moving bed biofilm reactor (ANMBBR)-biological aerated filter (BAF) system. Bioresource Technol 157: 223-230.

Zhang L, Liu M, Zhang S, Yang Y, Peng Y (2015) Integrated fixed-biofilm activated sludge reactor as a powerful tool to enrich anammox biofilm and granular sludge, Chemosphere 140: 114-118. 
634 Zhu X, Tian Y, Li F, Liu Y, Wang X, Hu X (2018) Preparation and application of magnetic 635 superhydrophobic polydivinylbenzene nanofibers for oil adsorption in wastewater, 636 Environ Sci Pollut Res 25: 22911-22919.

637

\section{Figure and Table captions}

639 Fig. 1. Adaptation and acclimation period of biomass $(\mathrm{pH} 7.0$ and induced current $=1 \mathrm{~mA})$.

640

Fig. 2. (a) Effect applied current on removal efficiency and (b) COD removal efficiencies under

641 different applied currents $(\mathrm{COD}=1500 \mathrm{mg} / \mathrm{L} ; \mathrm{pH} 7.0 ;$ reaction time $=3$ day $)$.

642 Fig. 3. (a) The effect of changes in the initial concentration of COD on the removal efficiency by

643 the bioelectrochemical process; (b) the removal efficiency of COD at different initial 644 concentrations (applied current intensity of $15 \mathrm{~mA}$ at ambient temperature).

645 Fig. 4. (a) The effect of HRT on removal efficiency of the bioelectrochemical process; (b) COD 646 removal efficiency at different reaction times $(\mathrm{COD}=1500 \mathrm{mg} / \mathrm{L}$ and applied current intensity $=$ $647 \quad 15 \mathrm{~mA})$.

648 Fig. 5. (a) Effect of different concentrations of $\mathrm{NaCl}$ on removal efficiency; (b) $\mathrm{COD}$ removal 649 efficiency at different $\mathrm{NaCl}$ concentrations $(\mathrm{COD}=1500 \mathrm{mg} / \mathrm{L}$ and applied current intensity $=$ $65015 \mathrm{~mA})$.

651 Fig. 6. a) Scanning electron microscopy photographes of bacteria in the biofilm, b) image of Gram652 stained bacteria.

653 Fig. 7. Comparison of COD removal efficiency with and without electric field. 
654 Fig. 8. Kinetic plots of the COD removal through the BER process: (a) the first-order model; (b) 655 the second-order (Grau) model; (c) the modified Stover-Kincannon model.

656 Table 1. Summary of Kinetic Parameters Based on the First-order, Second-order, and Stover657 Kincannon Models.

658 
Figures

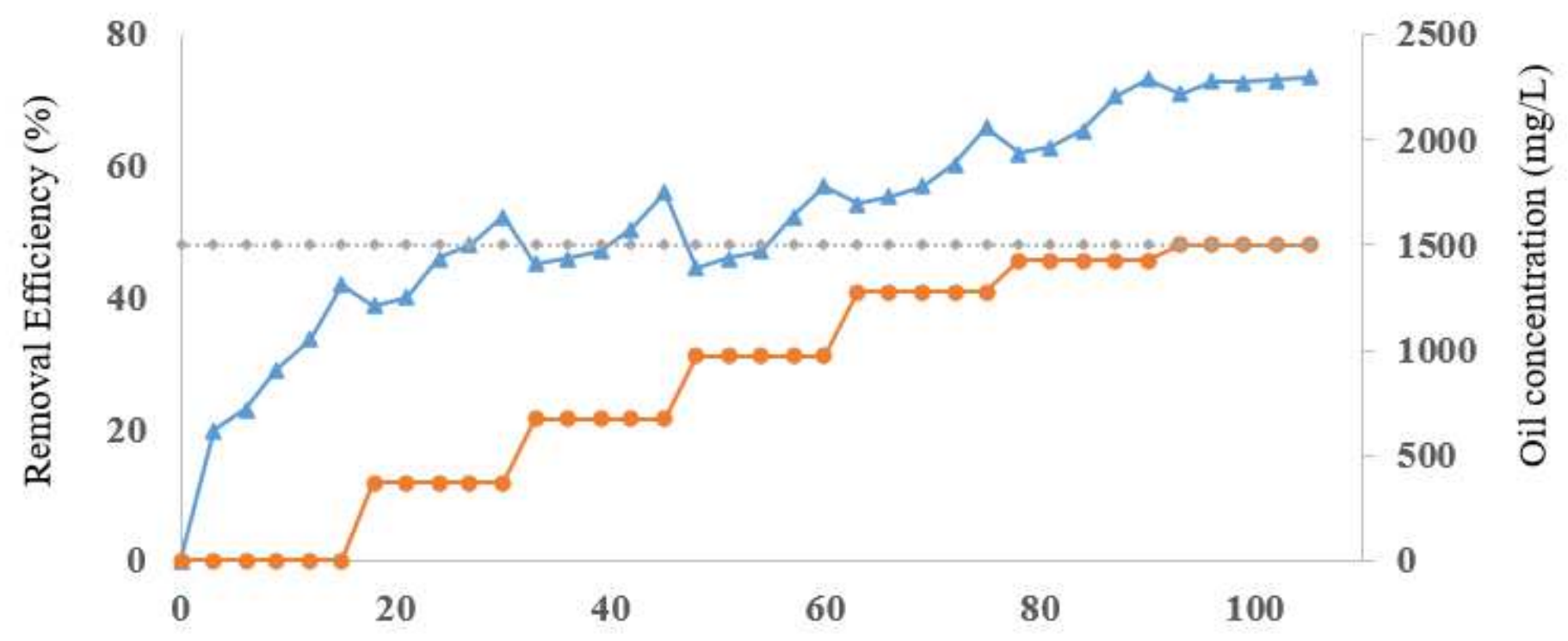

Acclimation Time(d)

$\longrightarrow$ Removal efficency $\quad \longrightarrow$ Concentration of oil $(\mathrm{mg} / \mathrm{L}) \quad \cdots \cdots \cdots \cdot \mathrm{COD}(\mathrm{mg} / \mathrm{l})$

\section{Figure 1}

Adaptation and acclimation period of biomass $(\mathrm{pH} 7.0$ and induced current $=1 \mathrm{~mA})$.
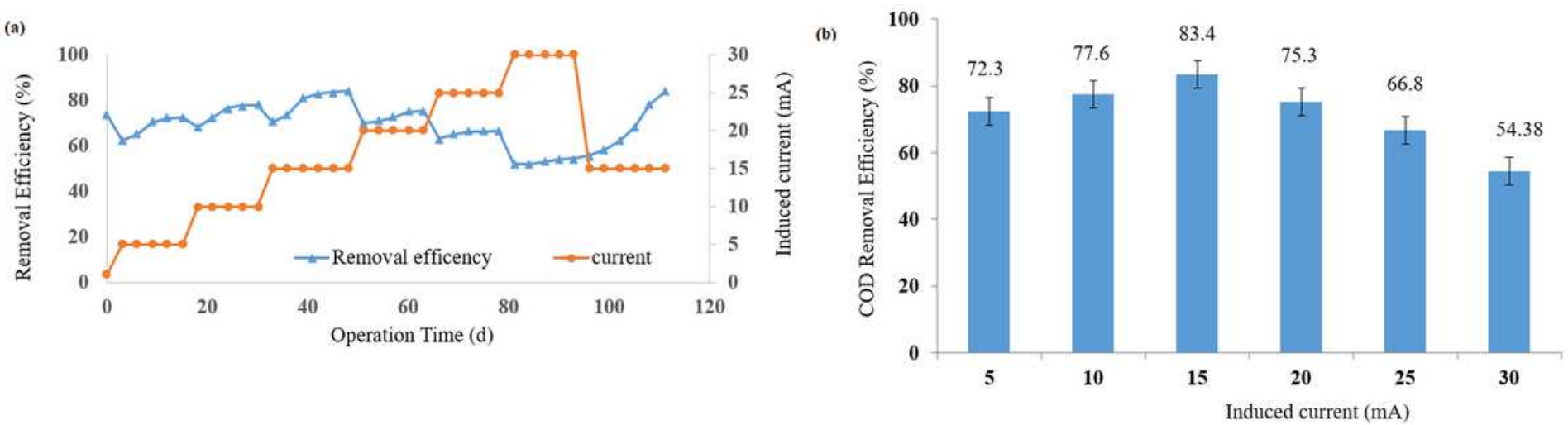

\section{Figure 2}

(a) Effect applied current on removal efficiency and (b) COD removal efficiencies under different applied currents $(\mathrm{COD}=1500 \mathrm{mg} / \mathrm{L} ; \mathrm{pH} 7.0$; reaction time $=3$ day $)$. 
(a)

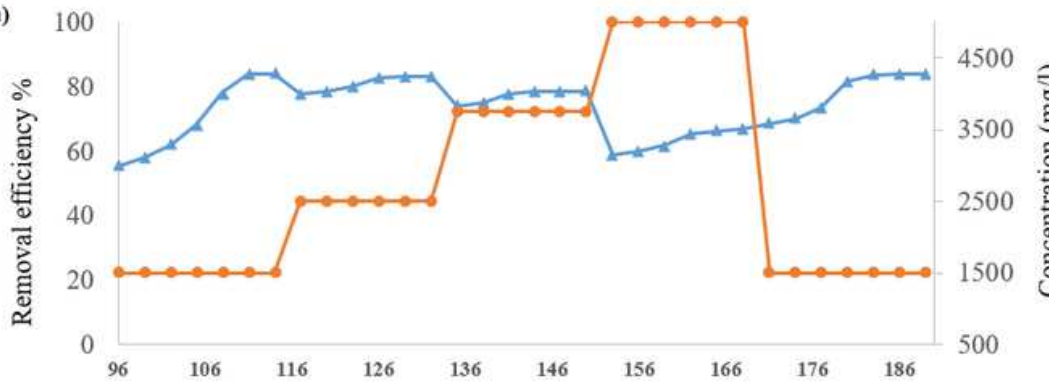

Operation Time (d)

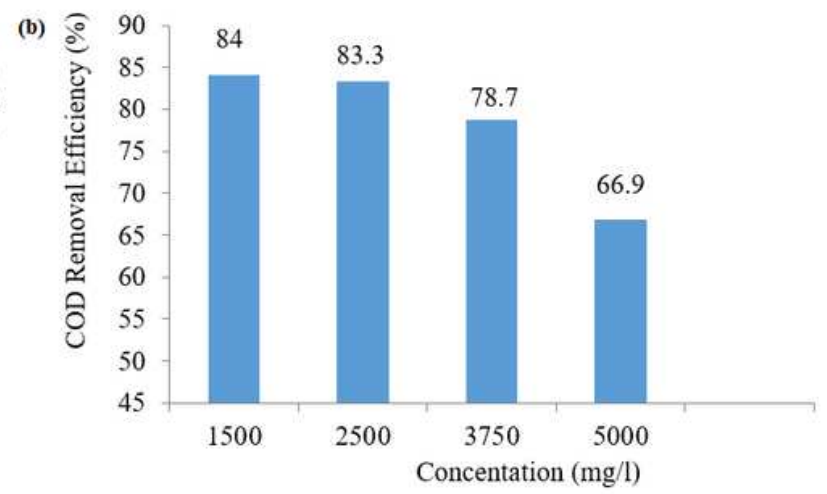

$\rightarrow$ Removal efficency $\rightarrow$ concentration

\section{Figure 3}

(a) The effect of changes in the initial concentration of COD on the removal efficiency by the bioelectrochemical process; (b) the removal efficiency of COD at different initial concentrations (applied current intensity of $15 \mathrm{~mA}$ at ambient temperature).

(a)

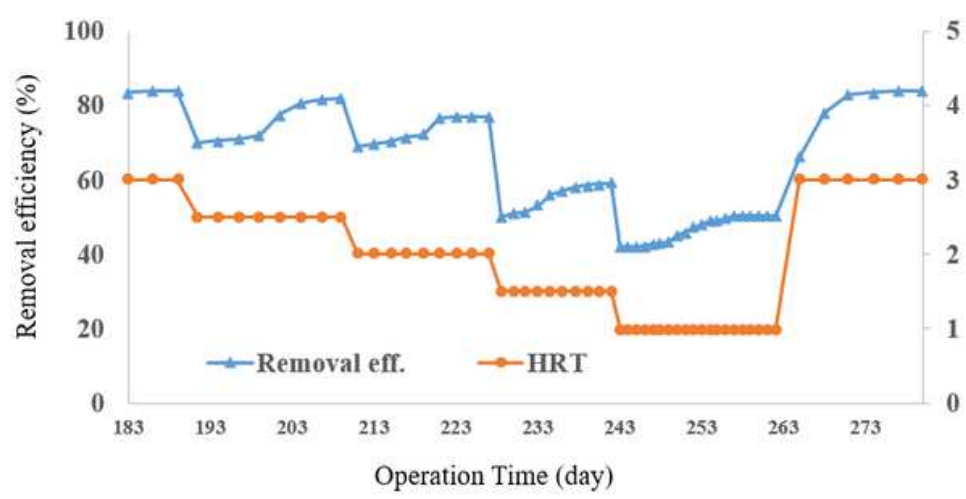

(b)

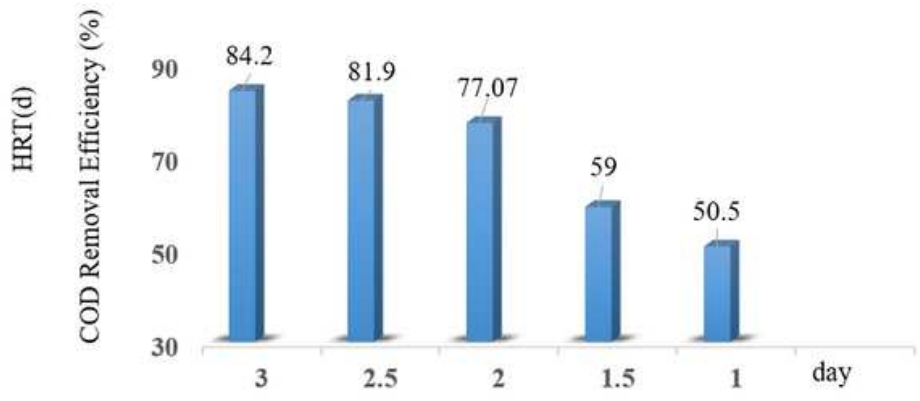

\section{Figure 4}

(a) The effect of HRT on removal efficiency of the bioelectrochemical process; (b) COD removal efficiency at different reaction times $(\mathrm{COD}=1500 \mathrm{mg} / \mathrm{L}$ and applied current intensity $=15 \mathrm{~mA}$ ). 
(a)

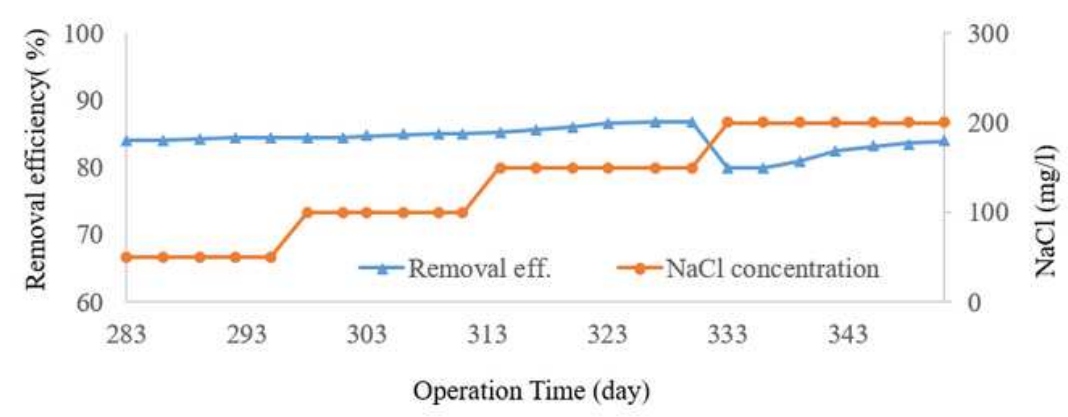

(b)

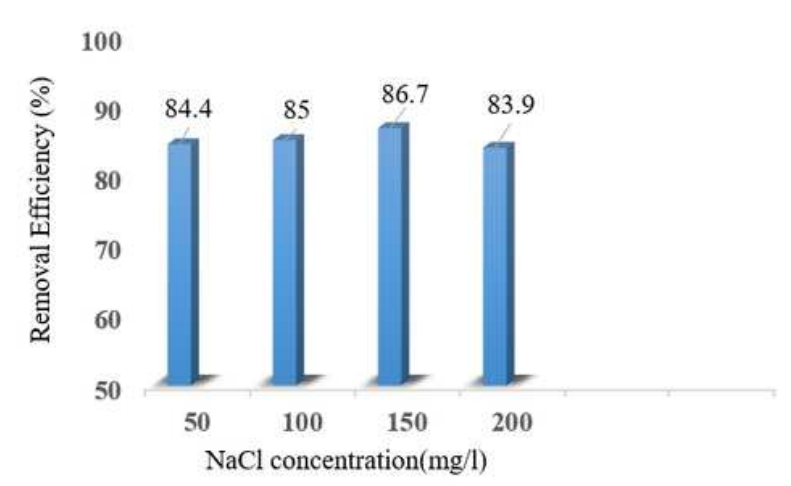

\section{Figure 5}

(a) Effect of different concentrations of $\mathrm{NaCl}$ on removal efficiency; (b) COD removal efficiency at different $\mathrm{NaCl}$ concentrations (COD $=1500 \mathrm{mg} / \mathrm{L}$ and applied current intensity $=15 \mathrm{~mA}$ ).

(a)

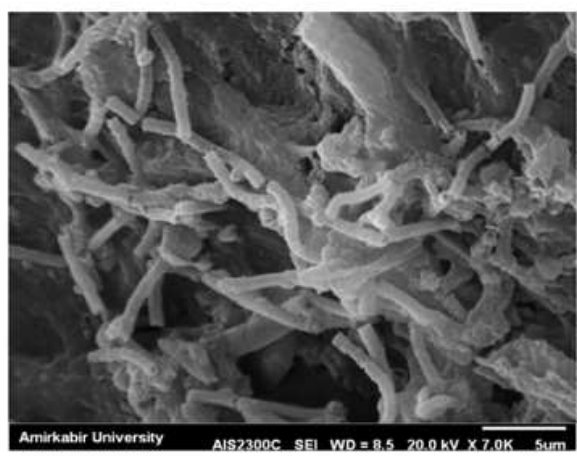

(b)

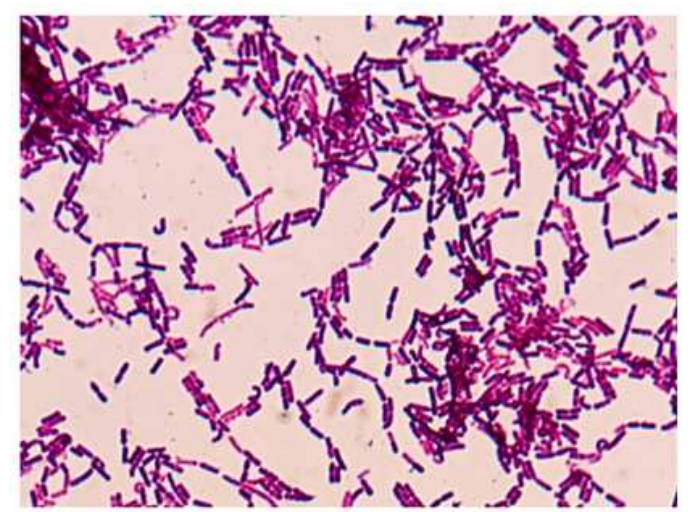

Figure 6

a) Scanning electron microscopy photographes of bacteria in the biofilm, b) image of Gramstained bacteria. 


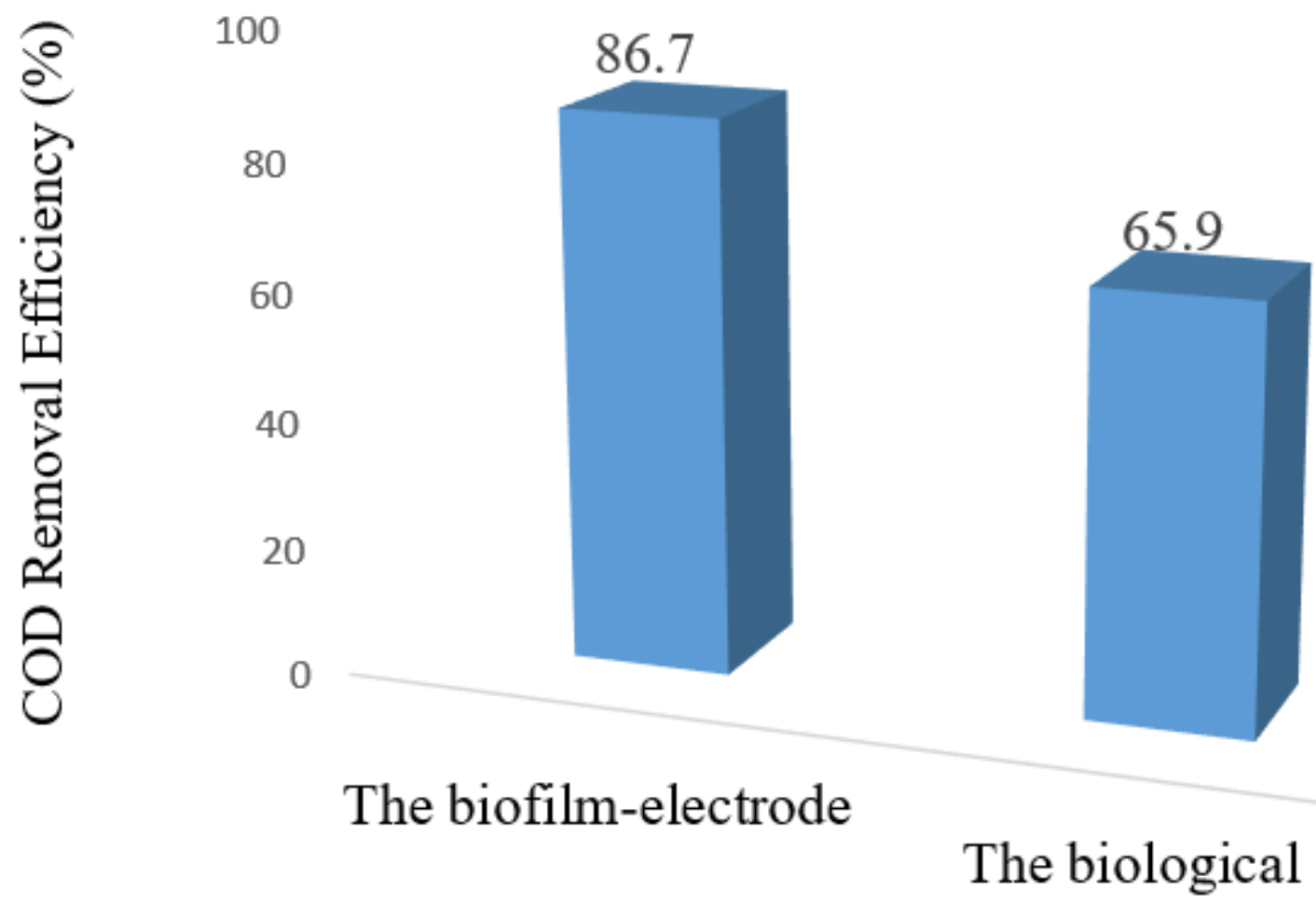

\section{Figure 7}

Comparison of COD removal efficiency with and without electric field.

(a)

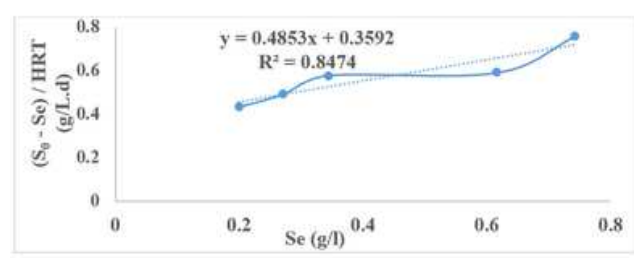

(b)

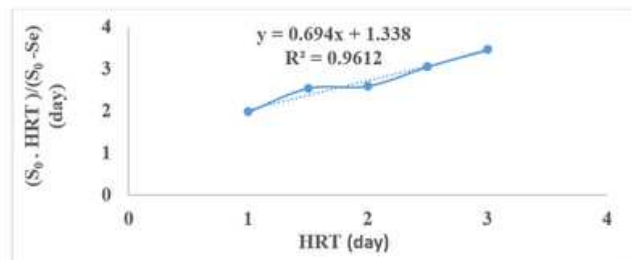

(c)

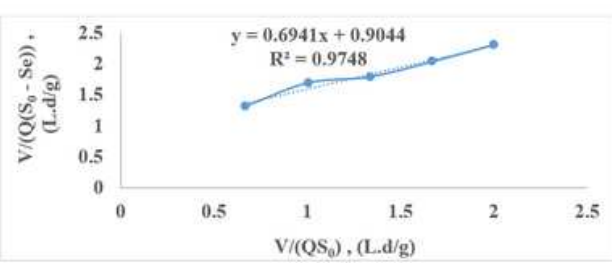

\section{Figure 8}

Kinetic plots of the COD removal through the BER process: (a) the first-order model; (b) the second-order (Grau) model; (c) the modified Stover-Kincannon model. 